\title{
Limitasi Stres Akademik Siswa SMP Negeri di Kabupten Barru
}

\author{
Taufik ${ }^{1}$ \\ Dosen STKIP Muhammadiyah Barru \\ Email: bumangnafiz@yahoo.com
}

\begin{abstract}
ABSTRAK
Penelitian dilakukan untuk mengungkapkan tingkat stress akademik siswa di SMP Negeri di kabupaten barru, penetilian ini lebih lanjut akan mengidentifikasi tingkat perbedaan stress akademik berdasarkan jenis kelamin dan lokasi sekolah. Penelitian ini berangkat dari peningkatan standar Ujian Nasional dari beberapa tahun terakhir, dan membebani aktivitas belajar siswa di Sekolah Menengah Pertama (SMP). Kondisi ini sebagai pemicu stres siswa, sejak lama, pengaruhnya terhadap belajar mereka. Berdasarkan hal tersebut, penelitian ini bertujuan untuk mengidentifikasi tingkat stres akademik siswa, dan perbedaan berdasarkan jenis kelamin, dan lokasi sekolah. Penelitian ini menggunakan Cluster Random Sampling. Sampel dikelompokkan menjadi 3 (tiga), yaitu sekolah yang terletak di pusat kota kabupaten, tengah kota dan pinggiran kota. Hasil penelitian menunjukkan bahwa terdapat 17\% siswa mengalami stres akademik pada tingkat rendah,73,4\% mengalami stres akademik pada tingkat sedang, dan 11,2\% siswa mengalami stres akademik pada tingkat tinggi. Tidak ada perbedaan yang signifikan antara stres akademik Siswa SMP Negeri di kabupaten barru berdasarkan lokasi dan jenis kelamin. Temuan penelitian ini kemudian dapat menjadi kebutuhan dasar yang penting akan layanan bimbingan dan konseling dalam rangka menurunkan tingkat stres siswa akademik dikabupaten barru, sehingga mereka dapat belajar dengan melakukan segala upaya yang optimal.
\end{abstract}

Kata Kunci: Stres akademik, konseling, Siswa

\section{Limitation Of Academic Stress For State SMP Students In Barru District}

\begin{abstract}
This study was conducted to reveal the level of academic stress of students in public junior high schools in Barru district, this research will further identify the different levels of academic stress based on gender and school location. in Junior High School (SMP). This condition has been a stressor for students, since a long time ago, the effect on their learning. Based on this, this study aims to identify students' academic stress levels, and differences by gender, and school location. This research uses Cluster Random Sampling. The sample is grouped into 3 (three), namely schools located in the district city center, downtown and suburbs. The results showed that there were $17 \%$ of students experienced academic stress at a low level,73.4\% experienced academic stress at a moderate level, and $11.2 \%$ students experienced academic stress at a high level. There is no significant difference between the
\end{abstract}


academic stress of State Junior High School students in Barru Regency based on location and gender. The findings of this study can then become an important basic need for guidance and counseling services in order to reduce the stress level of academic students in the new district, so that they can learn by making optimal efforts.

Keyword: Academic stress, counseling, Student

\section{PENDAHULUAN}

Masa remaja merupakan masa storm and stress, di mana merupakan masa yang bergolak dan berisi konflik serta perubahan suasana hati. (Payne, M. A. 2012; Arnett, J. J. 2006), yang dapat menyebabkan depresi (Byrne \& Mazanov, 2007; Deardorff \& Sandler, 2003; Lazaratou \& Soldatos , 2010). Kondisi ini disebabkan karena banyaknya goncangan-goncangan dan perubahan yang cukup radikal dari masa sebelumnya (Santrock, 2003; Hurlock, 1994). Perubahan tuntutan belajar dari masa sebelumnya juga menyebabkan munculnya gejala stress. Kondisi ini antara lain disebabkan oleh tuntutan yang tinggi terhadap prestasi siswa. Dari tahun ke tahun Kementerrian Pendidikan dan Kebudayaan menetapkan standar kelulusan yang selalu meningkat. Di samping itu pemerintah daerah kabupaten dan kota juga menuntutdan kadangkal menekan pihak sekolah agar mencapai prestasi yang tinggi serta tingkat kelulusan siswa yang harus mendekati $100 \%$. Di pihak lain beban belajar siswa di SMA juga ditrasa banyak. Tuntutan yang tinggi itu seringkali menjadi pemicu munculnya stres pada peserta didik,khususnya pada mereka yang tidak memiliki kesiapan dan kedisiplinan dalam belajar.

Menurut Baldwin (dalam Desmita, 2009) dalam menghadapi beban pelajaran yang dirasa cukup berat di sekolah akan dapat menimbulkan stress pada remaja, terutama bagi remaja high school, mengingat pada masa ini remaja pada umumnya mengalami tekanan dari pihak sekolah dan kadangkala dari orang tua untuk memperoleh nilai yang tinggi agar dapat melanjutkan pendidikan ke perguruan tinggi favorit. Lebih lanjut Rainham (dalam Desmita, 2009) menyatakan bahwa pada masa-masa sekolah menengah disatu sisi merupakan kesempatan untuk mendapatkan pengalaman yang sangat berharga bagi remaja, 
tetapi disisi lain mereka dihadapkan dengan banyaknya tuntutan dan perubahan yang cepat yang pada kahirnya dapat membuat mereka mengalami masa-masa yang penuh dengan stress.

Stres merupakan suatu kondisi yang disebabkan adanya ketidaksesuaian (Garniwa, I. 2007) antara situasi yang diinginkan dengan keadaan biologis, psikologis atau sistem sosial individu (Sarafino, 2006; Wardi, R., \& Ifdil, I. (2016). (Anggola \& Ongori 2009; Pratama, M. R., 2015; Siska, M., 2011) juga mendefinisikan stres sebagai persepsi dari kesenjangan antara tuntutan lingkungan dan kemampuan individu untuk memenuhinya. Robbins (2001) menyatakan bahwa stres merupakan suatu kondisi yang menekan keadaan psikis seseorang dalam mencapai sesuatu kesempatan di mana untuk mencapai kesempatan tersebut terdapat batasan atau penghalang. Weinberg dan Gould (2003) mendefinisikan stres sebagai "a substantial imbalance between demand (physical and psychological) and response capability, under condition where failure to meet that demand has importance concequences". Artinya, ada ketidakseimbangan antara tuntutan (fisik dan psikis) dan kemampuan memenuhinya. Gagal dalam memenuhi kebutuhan tersebut akan berdampak krusial. Sedana dengan sebelumnya (Mufadhal Barseli , Ifdil, Linda Fitria. 2020) Stress adalah respons organisme untuk menyesuaikan diri dengan tuntutan-tuntutan yang berlangsung. Tuntutan tersebut dapat berupa hal-hal yang faktual terjadi, atau hal-hal baru yang mungkin akan terjadi, tetapi dipersepsi secara aktual.

Stress akademik Stres yang terjadi di lingkungan sekolah atau pendidikan biasanya disebut dengan stres akademik (Sinaga, M. A. J. 2015; Rahmadani, C. S. M. 2014; Hikmah, Y. 2014; ). Desmita (2010) menyatakan "Stres akademik adalah stres yang disebabkan oleh academic stresor". Academic stresor adalah stres yang dialami siswa yang bersumber dari proses pembelajaran atau hal-hal yang berhubungan dengan kegiatan belajar seperti: tekanan untuk naik kelas, lama belajar, mencontek, banyak tugas, mendapat nilai ulangan.

Sebagian besar sumber stress siswa berasal dari masalah akademik (Elias, 2011). Stres di bidang akademik pada anak muncul ketika harapan untuk meraih 
prestasi akademik meningkat, baik dari orang tua, guru ataupun teman sebaya. Harapan tersebut seringkali tidak sesuai dengan kemampuan yang mereka miliki (Shahmohammadi, 2011). Di kalangan remaja Indonesia banyak ditemukan fenomena ketidakmampuan siswa mengelola stress. Akibatnya akan berbuntut pada hal-hal tragis seperi melarikan diri dan bunuh diri misalnya, seorang siswa shock dan bunuh diri karena tidak lulus UN (Kompasiana, 2011), Karena malu dengan nilai raport rendah, seorang siswi di bekasi menggantungkan diri (Ehan, 2011), Peristiwa di Medan seorang gadis bunuh diri dengan loncat dari lantai 4 sebuah plaza karena tidak naik kelas (Global Medan 2010). Dalam kurun waktu lima bulan terakhir sampai November 2011, di Kabupaten Banyumas terdapat 12 kasus bunuh diri dengan berbagai motif. Dari 12 kasus tersebut, lima kasus terbaru dilakukan oleh pelaku yang masih berusia remaja (Suara Merdeka, 2011). Angka kasus bunuh diri pada kalangan anak hingga remaja di Indonesia termasuk tinggi di Asia.

Menurut Organisasi Kesehatan Dunia WHO, pada 2005 tercatat 50 ribu penduduk Indonesia bunuh diri setiap tahun. Dari kejadian kasus bunuh diri tersebut, ternyata kasus yang paling tinggi terjadi pada rentang usia remaja hingga dewasa muda, yakni 15-24 tahun (Kompasiana.b, 2011).

Banyaknya kasus-kasus yang terjadi dan semakin banyak stresor yang timbul, semakin meningkat pula tingkat stres pada remaja. Oleh karenanya penelitian ini dilakukan merupakan langkah awal untuk mendeskripsi tingkat stress yang terjadi di SMP Negeri di kabupaten barru. Sehingga dapat menjadi data awal untuk menentukan langkah lanjut bagi terentasnya permasalahan stress di kalangan siswa.

\section{METODE PENELITIAN}

Jenis Penelitian yang digunakan adalah penelitian kuantitatif deskriptif (Marguerite et. Al., 2006: Kultar Singh, 2007) dengan populasi siswa SMP Negeri di kabupaten barru yang ada di Kota kabupaten barru. Sample diambil dengan menggunakan teknik Cluster Random Sampling, sampling yang dibagi menjadi 3 
(tiga) kelompok yaitu sekolah di pusat kabupaten kota, tengah kota dan pinggiran kota dengan total sampel 323 siswa. Intrumen digunakan Skala Stres Akademik (SSA). Data dianalisis dengan menggunakan statistik deskriptif dan untuk analisis perbedaan tingkat stress akademik berdasarkan jenis kelamin dan lokasi sekolah dilakukan ujibeda dengan menggunakan ANOVA dan t-test menggunakan SPSS Ver. 16.

\section{HASIL DAN PEMBAHASAN}

Berdasarkan hasil penelitian maka dapat diketahui bahwa tingkat stress akademik siswa di SMP Negeri di kabupaten barru, yaitu sebegai berikut:

\section{Tingkat Stres Siswa SMP Negeri kabupaten barru}

Setelah analisis statistik dengan, maka diperoleh data $17 \%$ siswa SMP Negeri Kabupaten barru berada pada tingkat stres akademik rendah, 73,4\% siswa SMP Negeri Kabupaten barru berada pada tingkat stres akademik sedang, 11,2\% siswa SMP Negeri Kabupaten barru berada pada tingkat stres akademik tinggi. Dapat disimpulkan bahwa siswa SMP Negeri Kabupaten barru yang mempunyai prosentase paling banyak adalah siswa yang berada dalam kategori tingkat stres akademik sedang $(73,4 \%)$.

\section{Tingkat stres akademikk siswa SMP Negeri Kabupaten barru berdasarkan jenis} kelamin.

Setelah dianalisis statistik maka dapat disimpulkan bahwa rata-rata tingkat stres siswa perempuan adalah 93.65 (kategori sedang), sedangkan siswa laki-laki adalah 94,30 (kategori sedang).

\section{Perbedaan tingkat stres akademik siswa SMP Negeri Kabupaten barru berdasarkan jenis kelamin.}

Setelah analisis statistik dengan, maka diperoleh data sebagai berikut menunjukkan bahwa nilai $\mathrm{F}$ untuk jenis kelamin dengan equal variance assumed adalah 2,502 dengan signifikansi 0, 231. Karena probabilitas >0,05 sehingga menunjukkan bahwa kedua varians dari populasi adalah sama. Oleh karena itu, nilai t-test yang akan dipakai berdasar kepada nilai equal variances 
assumed. Berdasarkan nilai t-test yang diperoleh terlihat bahwa thitung adalah $-0,813$ dengan signifikansi 0, 430. Oleh karena signifikansi 0, $430>0,05$ maka diperoleh kesimpulan bahwa tidak terdapat perbedaan yang signifikan antara tingkat stres akademik siswa laki-laki dan siswa perempuan, dengan kata lain tidak terdapat perbedaan yang signifikan tingkat stres akademik siswa dari jenis kelamin.

\section{Perbedaan tingkat Stress akademik siswa SMP Negeri Kabupaten barru berdasarkan lokasi sekolah.}

Setelah dianalisis statistik dengan rnenggunakan ANOVA dilakukan, maka diperoleh Nilai Mean menunjukkan tidak ada perbedaan yang besar tingkat stres akademik siswa antar masing- masing daerah yaitu rata-rata siswa yang berada di lokasi sekolah pinggiran kota berada dalam kategori tingkat stres akademik sedang (93.65), siswa yang berada di lokasi tengah kota berada dalam kategori tingkat stres akademik sedang (92.82), demikian juga siswa yang berada di lokasi sekolah pusat kota juga berada dalam kategori sedang (94.12).

Berdasarkan hasil penelitian, tingkat stres akademik siswa SMP Negeri di kabupaten barru tergolong berada dalam kategori tingkat stres akademik sedang yaitu sebesar 73,4 \%. Sementara itu 11,2 \% siswa SMP Negeri di kabupaten barru berada pada tingkat stres akademik tinggi dan $17 \%$ siswa SMP Negeri di kabupaten barru berada pada tingkat stres akademik rendah. Hal ini berarti bahwa kondisi siswa SMP Negeri di kabupaten barru merasakan kondisi stres akademik, akan tetapi mereka masih dapat mengontrol/mengelolanya. Siswa SMP Negeri di kabupaten barru masih dapat mengontrol situasi atau kondisi penyebab munculnya stres yang berkaitan dengan berbagai tuntutan akademis. Menurut Lazarus (1984), berpendapat bahwa sesuatu yang menimbulkan stres tergantung pada bagaimana individu menilai dan menginterpretasikan suatu kejadian secara kognitif. Penilaian kognitif (cognitive appraisal) yang digunakan Lazarus menggambarkan interpretasi individu terhadap kejadian-kejadian dalam hidup mereka sebagai sesuatu yang berbahaya, mengancam, atau menantang dan keyakinan mereka apakah mereka memiliki kemampuan untuk menghadapi suatu kejadian dengan efektif. Kemampuan siswa mengontrol situasi 
atau kondisi penyebab munculnya stres yang berkaitan dengan berbagai tuntutan akademis menurut pandangan L azarus (dalam Santrock, 2003) melalui dua langkah:

1) Penilaian primer (primary appraisal), mengartikan apakah suatu kejadian mengandung bahaya atau menyebabkan kehilangan, menimbulkan suatu ancaman akan bahaya di masa yang akan datang atau tantangan yang harus dihadapi.

2) Penilaian sekunder (secondary appraisal), mengevaluasi potensi atau kemampuan dan menentukan seberapa efektif potensi atau kemampuan yang dapat digunakan untuk menghadapi suatu kejadian.

Meskipun secara umum kondisi tingkat stres akademik siswa SMP Negeri di kabupaten barru berada pada kategori sedang, akan tetapi banyak juga diantara mereka yang berada dalam kategori tingkat stres akademik tinggi yaitu sebesar 11,2 \%. Hal ini berarti bahwa siswa SMP Negeri di kabupaten barru tidak luput dari kondisi stres akibat berbagai tuntutan akademik.

Selain hal tersebut, dalam hasil penelitian $17 \%$ siswa SMP Negeri di kabupaten barru berada pada tingkat stress akademik rendah. Dalam hal ini membuktikan bahwa stress akademik tidak sepenuhnya bermakna negative melainkan dapat bermakna positif dalam artian dapat sebagai tantangan untuk mengatasinya. Stress ini tidak membahayakan, malah sebaliknya diperlukan untuk meningkatkan kualitas diri dan prestasi belajar (Desmita, 2009). Seseorang yang menilai stress sebagai tantangan (Challenge) akan memiliki semangat yang tinggi, karena merasa tertantang berarti merasa positif terhadap tuntutan yang dihadapi (Cooper, 2004).

Dalam upaya mereduksi stres menurut Lazarus dan Folkman (Cooper, 2004; Kavanagh, 2005; Aldwin,2007, Larkin, Kevin T. 2005) ada dua strategi yang dilakukan seseorang dalam melakukan coping, yaitu:

1) Problem-focused coping adalah usaha mengatasi stres dengan cara mengatur atau mengubah masalah yang dihadapi dan lingkungan sekitar yang menjadi penyebab tekanan. 
2) Emotion-focused coping adalah usaha mengatasi stres dengan cara mengatur respon emosional dalam rangka menyesuaikan diri dengan dampak yang akan ditimbulkan oleh suatu kondisi atau situasi yang dianggap penuh tekanan.

Individu cenderung menggunakan problem focused coping untuk kondisi yang dapat dikontrolnya dan menggunakan Emotion focused coping dalam menghadapi masalah-masalah yang sulit dikontrol, namun terkadang individu juga menggunakan strategi coping tersebut secara bersamaan, meski tidak semua strategi coping juga dapat digunakan individu. Hal inilah yang dapat membuat seseorang terhindar atau mengalami stres akademik rendah.

Perbedaan tingkat stres akademik siswa SMP Negeri di kabupaten barru berdasarkan jenis kelamin.

Berdasarkan hasil penelitian menunjukkan tidak terdapat perbedaan yang signifikan antara tingkat stres akademik siswa laki-laki dan siswa perempuan. Nilai ttest yang diperoleh terlihat bahwa thitung adalah -0,813 dengan signifikansi 0, 430. Oleh karena signifikansi 0,430>0,05 maka diperoleh kesimpulan bahwa tidak terdapat perbedaan yang signifikan antara tingkat stres akademik siswa laki-laki dan siswa perempuan, dengan kata lain tidak terdapat perbedaan yang signifikan tingkat stres akademik siswa dari jenis kelamin. Hal ini berarti kondisi tingkat stres siswa baik siswa perempuan dan siswa laki-laki berada dalam kategori hampir sama atau perbedaannya tidak signifikan, meskipun secara gambaran umum nilai rata-rata keduanya berbeda rata-rata tingkat stres siswa perempuan adalah 93,65 sedangkan siswa laki-laki adalah 94,30.

Hasil penelitian ini mendukung penelitian Leadbeater (1999) yang menunjukkan bahwa reaktivitas stres tidak berbeda antara anak perempuan dan anak laki-laki. Namun hasil penelitian ini juga bertolak belakang dengan hasil penelitian Liu (2011) dalam penelitiannya melalui analisis regresi multinomial mengungkapkan bahwa siswi perempuan memiliki tingkat orientasi prestasi lebih tinggi di sekolah sehingga menyebabkan gejala stress yang lebih sering. Beberapa studi menunjukkan bahwa perempuan lebih menanggapi terhadap stresordaripada anak laki-laki (Ge et all, 1994; Hankin, et al, 2007; MacKinnon, et all, 2002 ). 
Menurut Lazarus (1984) pria cenderung menggunakan problem focused coping karena pria menggunakan rasio atau logika sehingga mereka memilih untuk langsung menyelesaikan masalah yang dihadapi atau langsung mengahdapi sumber stres. Sedangkan wanita dikatakan lebih cenderung menggunakan emotion focused coping karena mereka lebih emosional sehingga cenderung untuk mengatur emosi emosi mereka dalam mengahadapi sumber stres. Perbedaan tingkat stres akademik siswa SMP Negeri di kabupaten barru berdasarkan lokasi sekolah. Berdasarkan hasil analisis diperoleh terlihat bahwa t hitung adalah 1,424 dengan signifikansi 0, 242. Oleh karena signifikansi 0,242 > 0,05 maka diperoleh kesimpulan bahwa tidak terdapat perbedaan yang signifikan antara tingkat stres akademik siswa yang berada pada sekolah yang berlokasi di pusat kota, tengah kota dan pinggiran kota, dengan kata lain tidak ada perbedaan tingkat stres akademik siswa berdasarkan daerah belajar. Meskipun secara gambaran umum nilai rata-rata tingkat stres akademik di ketiga daerah sekolah tersebut berbeda yaitu siswa yang berada di lokasi sekolah pusat kota dalam kategori sedang lebih tinggi (93.65) dari pada siswa yang berada di lokasi sekolah pinggiran kota yaitu rata-rata 92.82 dan rata-rata siswa yang berada di lokasi tengah kota 94.12.

\section{KESIMPULAN}

Berdasarkan hasil Penelitian ini maka dapat di simpulkan bahwa tingkat stress akademik yang terjadi pada siswa SMP Negeri di kabupaten barru berada pada tingkat sedang dan tingkat tinggi, sehingga penelitian ini memerlukan rekomendasikan terhadap layanan bimbingan dan konseling untuk menurunkan level stress yang dialami siswa dan bahkan pelayanan hingga menghilangkan stress academik yang dialami siswa. Siswa memperoleh bantuan untuk mengelola stress yang dialaminya, sehingga fungsinya sebagai siswa dapat di dilakukan secara optimalkan. 


\section{DAFTAR PUSTAKA}

Arnett, J. J. (2006). G. Stanley Hall's Adolescence: Brilliance and nonsense. History of Psychology, 9, 186-197.

Anggola, J.E., \& Ongori, H. 2009. "An Asessment of Academic Stress Among Undergraduate Students: The case of university of botswana". Educational research and reviews, 4 (2): 063-070.

Byrne, D. G., Davenport, S. C., \& Mazanov, J. (2007). Profiles of adolescent stress: The development of the adolescent stress questionnaire (ASQ). Journal of Adolescence, 30, 393-416.

Cooper, Cary. (2004). A brief history of stress. India: Blackwell Publishing.

Deardorff, J., Gonzales, N. A., \& Sandler, I. N. (2003). Control beliefs as a mediator of the relationship between stress and depressive symptoms among inner city adolescents. Journal of Abnormal Child Psychology, 31, 205-217.

Desmita. (2005). Hubungan Antara Stress Sekolah Dengan Derajat Stress dan Strategi Penanggulangan Pada Siswa MAN Model Bukittinggi. Tesis. Bandung: Universitas Padjajaran

Ehan. (2011). Bullying Dalam Pendidikan. Bandung: Universitas Pendidikan Indonesia

Elias. (2011). Stress and academic achievement students. Journal Of Social And Behavioral Sciences. 29, 646- 655.

Garniwa, I. 2007. Pengaruh stress kerja terhadap motivasi serta dampaknya terhadap prestasi kerja sdosen tetap universitas widyatama.

Ge, X., Lorenz, F. O., Conger, R. D., Elder, G. H., \& Simons, R. L. (1994). Trajectories of stressful life events and depressive symptoms during adolescence. Developmental Psychology, 30, 467-483.

Global Medan. (2010). Stres Tidak Naik Kelas, Loncat dari Lantai 4 Plaza Medan Fair (Online) (http://m.citi- talk.com/read.php?nid=1078 di akses 20 Maret 2013)

Hankin \& Abramson. (1998). Development of depression from preadolescence to young adulthood:Emerging gender differences in a 10-year longitudinal study. Journal of Abnormal Psychology. 107, 128-140 .

Hurlock, B. E. (1994). Psikologi Perkembangan. Alih bahasa: Sijabat, M.R Jakarta: Erlangga.

Kompasiana, (2011). Ujian Nasional antara prestasi atau sekedar lulus. (online) (www.kompasiana.com diakses 6 Maret 2021). 
Kompasiana.b. 2011. Kasus Bunuh Diri Kembali Marak di Jakarta.( Online ) http://sosbud.kompasiana.com/2011/09/29/kasus-bunuh-diri-kembali-marakdi-jakarta di akses 20 Maret 2013

Kultar Singh. (2007). Quantitative Social Research Methods, Singapore:Sage Publications Asia-Pasific.

Leadbeater, B. J., Kuperminc, G. P., Hertzog, C., \& Blatt, S. J. (1999). A multivariate model of gender differences in adolescents' internalizing and externalizing disorders. Developmental Psychology, 35, 1268-1282.

Liu, Y., \& Lu, Z. (2011). The Chinese high school student's stress in the school and academic achievement. Educational Psychology: An International Journal of Experimental Educational Psychology, 31(1), 27- 35.

MacKinnon, D. P., Lockwood, C. M., Hoffman, J. M., West, S. G., \& Sheets, V. (2002). A comparison of methods to test mediation and other intervening variable effects. Psychological Methods, 7, 83-104.

Mufadhal Barseli , Ifdil , Linda Fitria. 2020. Stress akademik akibat Covid-19. jurnal penelitian guru Indonesia. Vol.5 no.2. Indonesian Institute for Counseling, Education and Theraphy. Padang

Payne, M. A. (2012). "all gas and no brakes!": Helpful metaphor or harmful stereotype? Journal of Adolescent Research, 27(1), 3-17.

Robbins, Stephen P. (2001). Perilaku Organisasi: Konsep, Kontroversi, Aplikasi, Jilid I. Edisi 8, Prenhallindo Jakarta.

Santrock, J. (2003). Adolescance : Ninth Edition. New York :McGraw-Hill Companies Inc.

Sarafino, E.P. (1994). Health Psychology Biopsychosocial Interaction. USA: John Wiley \& Sons . 2006. Health Psychology: Biopsychosocial interactions. Fifth.

Shahmohammadi. (2011). Students' coping with stress at hight school level particulary at 11th \& 12th grade. Jurnal social and behavioral sciences. 30, 395-401.

Sinaga, M. A. J. 2(015). Stres Akademik antara Anak Taman Kanak-kanak yang Mendapat Pengajaran Membaca dan Tidak Mendapat Pengajaran Membaca (Doctoral dissertation, Program Studi Psikologi FPSI-UKSW).

Suara Merdeka. (2011). Peningkatan Angka Bunuh Diri (Online) http://suaramerdeka.com/vl/index.php/read/news/Peningkatan- AngkaBunuh-Diri- . Di akses 20 Maret 2021)

Weinberg RS, Gould D. 2003. Foundations of Sport \& Exercise Psychology. Champaign, IL:Human Kinetics. 